\title{
Conceptual Influences on Grammatical Planning Units
}

\author{
Antje S. Meyer \\ Max Planck Institute for Psycholinguistics, Nijmegen, The Netherlands
}

\section{INTRODUCTION}

Most theories of language production assume that speakers plan utterances in parallel at different levels while speaking at the same time. The main planning levels most commonly assumed are a conceptual level specifying the utterance content, a syntactic (or semantic-syntactic) level, and a level of utterance form (e.g. Bock \& Levelt, 1994; Levelt, 1989). The experiments reported below are part of a research project investigating how the planning processes are coordinated with each other and with the articulation of the utterance. Most likely, the coordination depends on conceptual and grammatical factors. The research strategy is to investigate the impact of these two types of factors on the size of the planning units used for different utterance types.

Earlier experiments (Meyer, 1996) investigated the size of the grammatical and phonological planning units for noun phrase conjunctions such as "the dog and the baby" and short sentences such as "the dog is next to the baby". The picture-word interference paradigm described below was used. The results showed that for both utterance types, the lemmas (i.e. syntactic specifications) of both nouns and the form of the first noun were selected before utterance onset. The form of the second noun was only selected after utterance onset. These findings are compatible with results of speech error analyses (e.g. Garrett, 1980, 1982) and earlier experimental studies (e.g. Dell \& O'Seaghdha, 1992; Levelt \& Maassen, 1981) that had also demonstrated the planning units to be larger at the grammatical than at the form level.

Requests for reprints should be addressed to Antje S. Meyer, Max Planck Institute for Psycholinguistics, Postbus 310, 6500 AH Nijmegen, The Netherlands. E-mail: asmeyer@mpi.nl

I thank Godelieve Hofstee, Ingrid Schophuis, and Marianne Wissink for preparing the stimulus materials and running the experiments. 
The experiments reported below investigated the grammatical planning units for slightly more complex utterances, namely conjunctions of adjective-noun phrases such as "the big dog and the little baby". The main question was whether the grammatical planning unit constructed before utterance onset would still include both nouns, or whether, due to increased conceptual and/or syntactic complexity, smaller units would be used.

\section{EXPERIMENT 1}

\section{Method}

The picture-word interference paradigm was used. Participants were presented with drawings of object pairs, which they described in phrases such as "the big dog and the little baby" naming the left object first. Each picture was accompanied by a distractor word that was semantically related to the name of the left or right object or unrelated to both. We examined whether a semantic interference effect (longer mean reaction times after related than unrelated distractors) would only be obtained for the first noun, which would indicate that only this noun, but not the second noun, is selected before utterance onset, or for both nouns, which would indicate that both nouns are selected before utterance onset.

Participants. Thirty-two undergradua te students, whose native language was Dutch, participated in the experiment.

Materials. The visual stimuli were 20 line drawings of pairs of objects shown next to each other. There were a small and a large version of each object with vertical visual angles of under $3^{\circ}$ and above $6^{\circ}$, respectively. Each object pair included one small and one big object. There were four versions of each pair differing in which object appeared on the left and which on the right side of the display, and which object was shown in the large and which in the small version. For each object, a related distractor that was a member of the same semantic category and an unrelated distractor were selected. Distractors were presented auditorily and began at picture onset ( $\mathrm{SOA}=0$ $\mathrm{msec})$ or $150 \mathrm{msec}$ later $(\mathrm{SOA}=150 \mathrm{msec})$.

Design. Stimulus onset asynchrony (SOA) was tested between participants. Each participant saw two versions of each object pair that differed in which object was small and which one large. Thus, each participant saw 40 different pictures. Versions differing in the left-right ordering of the objects were presented to different groups of participants. Each participant saw each picture four times, each time in combination with 
a different distractor. The order of testing different distractor types was counterbalanced across pictures and participants.

Procedure. On each test trial, an experimental picture was presented for $800 \mathrm{msec}$. The auditory distractor began at picture onset or $150 \mathrm{msec}$ later. The inter-trial interval was $3500 \mathrm{msec}$. Speech onset latencies were recorded using a voicekey.

Pretest of the Materials. In a pretest of the materials, all drawings were displayed at approximately the same size covering a vertical visual angle of about $4^{\circ}$. The participants described them in noun-phrase conjunctions such as "the dog and the baby". The procedure was the same as in the main experiment. A significant interaction of relatedness and SOA was obtained $\left[F_{1}(1,30)=11.68, \mathrm{MSe}=770 ; F_{2}(1,19)=16.54, \mathrm{MSe}=680\right.$; both $\left.P<0.01\right]$. Analyses of simple effects showed that the semantic interference effect was only significant at the SOA of $150 \mathrm{msec}\left[F_{1}(1,30)=35.03\right.$, MSe $=767$; $F_{2}(1,19)=54.98, \mathrm{MSe}=613$; both $\left.P<0.01\right]$. At that SOA, interference effects of 48 and $34 \mathrm{msec}$ were found for the first and second noun, respectively. The interaction of relatedness and position was not significant. These findings replicate the results of Meyer (1996) and show that when drawings of objects not varying greatly in size are named in noun phrase conjunctions, the initial grammatical encoding unit usually includes both nouns.

\section{Results}

In Experiment 1, no main effect of SOA or interaction involving this variable was obtained. A significant semantic interference effect of $26 \mathrm{msec}$ was obtained for the first noun [means: 733 vs $709 \mathrm{msec} ; F_{1}(1,30)=20.79$, MSe $=1034 ; F_{2}(1,19)=21.47$, MSe $=1252$; both $\left.P<0.01\right]$, whereas the speech onset latencies after related $v s$ unrelated distractors pertaining to the second noun differed by only $1 \mathrm{msec}$ (means: 724 vs $723 \mathrm{msec}$ ). The interaction of relatedness and position was highly significant $\left[F_{1}(1,30)=\right.$ $10.42, \mathrm{MSe}=947 ; F_{2}(1,19)=18.30, \mathrm{MSe}=674$; both $\left.P<0.01\right]$. These results indicate that on most trials only the first, not the second, noun lemma was selected before utterance onset. Given that the interference effect for the first noun was weaker than in the pretest, it is possible that even the first noun was not selected before utterance onset on all trials.

\section{EXPERIMENT 2}

Experiment 1 differed from the pretest and earlier related experiments in two major ways: the drawings differed in size, and the participants' utterances included size adjectives in addition to nouns. The second 
experiment investigated which of these differences was responsible for the change in the size of the grammatical planning units.

\section{Method}

The same method was used as in Experiment 1, except that participants were instructed to produce noun phrase conjunctions only including the two object names (e.g. "the dog and the baby").

\section{Results}

The results were similar to those of Experiment 1. For the first noun, a significant interference effect of $24 \mathrm{msec}$ was obtained [means: 740 vs 716 $\operatorname{msec} ; F_{1}(1,30)=14.34, \mathrm{MSe}=1232 ; F_{2}(1,19)=9.67, \mathrm{MSe}=2284 ;$ both $P<$ $0.01]$, whereas the interference effect for the second noun only amounted to an insignificant $9 \mathrm{msec}$ (means: 733 vs $724 \mathrm{msec}$ ). The interaction of relatedness and position just failed to reach significance $\left[F_{1}(1,30)=3.96\right.$, $\left.\mathrm{MSe}=889, P<0.06 ; F_{2}(1,19)=3.21, \mathrm{MSe}=1374, P<0.09\right]$. Thus, although the utterance complexity was reduced, the participants in this experiment were not more inclined than those in Experiment 1 to select the second noun before speech onset.

\section{CONCLUSIONS}

When participants described pairs of objects of approximately the same size in noun phrase conjunctions, such as "the dog and the baby", both nouns were included in the initial grammatical planning unit. By contrast, when the objects varied in size, the initial planning unit only included the first noun, regardless of whether the participants mentioned the size of the objects or not. Although it is unknown how exactly the decrease in the size of the planning units came about, it can be concluded that it must be due to visual or conceptual rather than linguistic factors. Earlier experiments (Meyer, 1996) had shown that the grammatical planning units remained stable when the syntactic structure of the utterances changed. These and the present results do not rule out that syntactic structure can affect grammatical planning units, but they suggest that syntactic structure is not the only, and maybe not the most important, determinant of these units.

\section{REFERENCES}

Bock, K., \& Levelt, W. (1994). Grammatical encoding. In M.A. Gernsbacher (Ed.), Handbook of psycholinguistics, pp. 945-984. San Diego, CA: Academic Press.

Dell, G.S., \& O'Seaghdha, P.G. (1992). Stages of lexical access in language production. Cognition, 42, 287-314. 
Garrett, M.F. (1980). Levels of processing in sentence production. In B. Butterworth (Ed.), Language production, Vol. 1: Speech and talk, pp. 177-234. New York: Academic Press.

Garrett, M.F. (1982). Production of speech: Observation from normal and pathological language use. In A. Ellis (Ed.), Normality and pathology in cognitive functions, pp. 19-76. London: Academic Press.

Levelt, W.J.M. (1989). Speaking: From intention to articulation. Cambridge, MA: MIT Press.

Levelt, W., \& Maassen, B. (1981). Lexical search and order of mention in sentence production. In W. Klein \& W. Levelt (Eds), Crossing the boundaries in linguistics, pp. 221-252. Dordrecht: Reidel.

Meyer, A.S. (1996). Lexical access in phrase and sentence production: Results from picture-word interference experiments. Journal of Memory and Language, 35, 477-496. 
